\title{
Role of filling materials in a P-wave interaction with a rock fracture
}

\author{
W. Wu ${ }^{\text {a,* }}$, J.C. Li $^{\text {b }}$, J. Zhao ${ }^{\mathrm{a}}$ \\ a Ecole Polytechnique Fédérale de Lausanne (EPFL), School of Architecture, Civil and Environmental Engineering, Laboratory of Rock Mechanics (LMR), CH-1015 Lausanne, Switzerland \\ b State Key Laboratory of Geomechanics and Geotechnical Engineering, Institute of Rock and Soil Mechanics, Chinese Academy of Sciences, Wuhan 430071, China
}

\section{A R T I C L E I N F O}

Article history:

Received 30 April 2013

Received in revised form 7 January 2014

Accepted 25 January 2014

Available online 9 February 2014

\section{Keywords:}

Rock fracture

Seismic attenuation

Filling materials

Packing mechanism

\begin{abstract}
A B S T R A C T
The purpose of this study is to investigate the role of filling materials (e.g., quartz sand and kaolin clay) in the interaction between a P-wave and a rock fracture. The specific fracture stiffness reflects the seismic response of a filled fracture, while the wave transmission coefficient describes P-wave transmission across the filled fracture. A series of experimental tests using a split Hopkinson rock bar technique are conducted on artificial rock fractures that are filled with pure quartz sand, sand-clay mixtures with $30 \%, 50 \%$ and $70 \%$ clay weight fractions, and a pure clay matrix. The boundary conditions of the filled fracture, i.e., the displacement and stress discontinuities, are used in the method of characteristic lines to calculate the wave transmission coefficient in the time domain. The analytical results agree well with the experimental results. The specific fracture stiffness and the wave transmission coefficient decrease with increasing filling material thickness. When the clay matrix completely fills the void space of the quartz sand, the filled fracture exhibits the largest specific fracture stiffness and promotes P-wave transmission. In general, the wave transmission coefficient is strongly related to the specific fracture stiffness, regardless of the filling material composition or the filling material thickness.
\end{abstract}

(c) 2014 Elsevier B.V. All rights reserved.

\section{Introduction}

When seismic waves propagate through rock masses, rock fractures attenuate the wave amplitude and decrease the wave velocity. Natural fractures are often filled with weak materials, e.g., sand and clay. These filling materials and their mixtures influence the mechanical and physical behaviors of rock fractures, such as strength, porosity and permeability (Crawford et al., 2008). During seismic wave propagation across a filled fracture, wave attenuation is mainly determined by the dynamic compaction of filling materials and by wave reflection and transmission at fracture interfaces (Wu et al., 2013a,b). The seismic response of a filled fracture, such as opening and closure, may induce rock mass collapse. The interaction between a P-wave and a filled fracture is thus important to assess seismic energy radiation and rock mass instability.

A previous study (Wu et al., 2013c) investigated the effects of the fracture thickness, the particle size of the filling sand and the loading rate of an incident wave on the dynamic properties of a filled fracture. The fracture properties and the loading conditions affect the dynamic compaction of filling materials. The dynamic compaction also depends on filling material types. For instance, when a P-wave propagates across a filled fracture, the wave transmission coefficient for a clay-filled fracture is smaller than that for a sand-filled fracture (Ma et al., 2011). Moreover, a filled fracture often contains the mixture of weak materials. These component materials exhibit different dynamic responses and have different roles in wave transmission. Hence, understanding the

\footnotetext{
* Corresponding author. Tel.: + 41 216933962; fax: +41216934153.

E-mail address: wei.wu@epfl.ch (W.Wu).
}

dynamic compaction of filling materials and their mixtures is necessary to estimate the seismic response of a filled fracture and the wave transmission across the filled fracture.

This study follows the previous study (Wu et al., 2013c), utilizing the displacement and stress discontinuity model (DSDM) in the analytical prediction and employing the split Hopkinson rock bar (SHRB) in the experimental work. The purpose of this study is to investigate the role of filling materials in the interaction between a P-wave and a filled fracture. The P-wave transmission and the fracture response are described by the wave transmission coefficient and by the specific fracture stiffness, respectively. The wave transmission coefficient shows the portion of an incident energy that can pass through the filled fracture, and the specific fracture stiffness means dynamic stress change per unit fracture closure. The DSDM calculation is performed based on the method of characteristic lines. The wave transmission coefficient is thus calculated in the time domain to compare with the experimental results from a real-time measurement. A series of SHRB tests are conducted on fractures filled with pure quartz sand, sand-clay mixtures with $30 \%, 50 \%$ and $70 \%$ clay weight fractions, and a pure clay matrix. The clay weight percentage is controlled during the preparation of the filling materials. The filling materials are three phase media with mixed solids, water and air. The filled fracture is tested under an air-dry condition.

\section{Analytical model}

The method of characteristic lines is commonly used to express the relation between the particle velocity-time response $v(x, t)$ and the stress-time response $\sigma(x, t)$ during one-dimensional P-wave propagation in the time domain (Bedford and Drumheller, 1994). In an $x-t$ 
plane ( $x$ is the distance and $t$ is the time), Fig. 1 shows the conjunction points of the characteristic lines for the right- and left-running waves across a filled fracture at a distance $x_{i}$. Zhao et al. (2006) show that the responses at point $a$ are determined by those at points $b, c$ and $d$ and the responses at time $t_{j+1}$ can be derived from those at time $t_{j}$. In this study, we use the known responses at points $b$ and $d$ (or points $c$ and d) to calculate the particle velocity-time responses at the front (or rear) interface of the filled fracture. The method defines that the quantity $z v(x, t)+\sigma(x, t)$ is constant along the right-running characteristic line $a b$ with slope $1 / c$

$z v^{-}\left(x_{i}, t_{j+1}\right)+\sigma^{-}\left(x_{i}, t_{j+1}\right)=z v^{+}\left(x_{i-1}, t_{j}\right)+\sigma^{+}\left(x_{i-1}, t_{j}\right)$

and the quantity $z v(x, t)-\sigma(x, t)$ is constant along the left-running characteristic line $a c$ with slope $-1 / c$

$z v^{+}\left(x_{i}, t_{j+1}\right)-\sigma^{+}\left(x_{i}, t_{j+1}\right)=z v^{-}\left(x_{i+1}, t_{j}\right)-\sigma^{-}\left(x_{i+1}, t_{j}\right)$

where $z$ is the P-wave impedance in the rock material, $z=\rho c, \rho$ and $c$ are the rock density and the P-wave velocity in the rock material, respectively, and $v^{-}\left(x_{i}, t_{j}+1\right)$ and $v^{+}\left(x_{i}, t_{j+1}\right)$ are the particle velocity-time responses at the front and rear interfaces at time $t_{j+1}$, respectively. Similarly, $\sigma^{-}\left(x_{i}, t_{j+1}\right)$ and $\sigma^{+}\left(x_{i}, t_{j+1}\right)$ are the stresstime responses at the front and rear interfaces at time $t_{j+1}$, respectively.

It should be noted that the P-wave in the system consists of a positive wave (a right running-characteristic line), $\varepsilon^{p}(t)$, for the compressive strain-time response and a negative wave (a left-running characteristic line), $\varepsilon^{n}(t)$, for the tensile strain-time response. The displacement-time responses at the front and rear interfaces are $u^{-}(x, t)$ and $u^{+}(x, t)$, respectively.

In the DSDM (Zhu et al., 2011), the stress discontinuity across the filled fracture is

$\sigma^{-}\left(x_{i}, t_{j}\right)-\sigma^{+}\left(x_{i}, t_{j}\right)=-\omega^{2} m_{n} u^{+}\left(x_{i}, t_{j}\right)$

where $\omega$ is the wave angular frequency and $m_{n}$ is the initial mass of the filling materials.

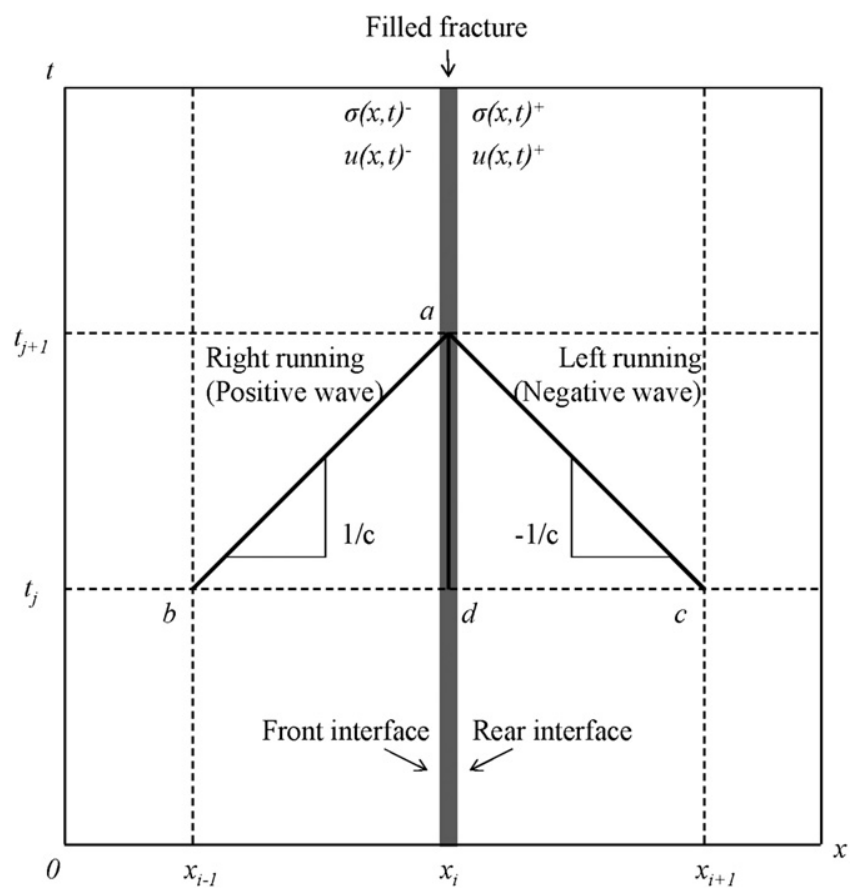

Fig. 1. Conjunction points of the characteristic lines for the right-running (positive) and left-running (negative) waves across a filled fracture at a distance $x_{i}$ in an $x-t$ plane.
The displacement discontinuity is

$u^{-}\left(x_{i}, t_{j}\right)-u^{+}\left(x_{i}, t_{j}\right)=\frac{\sigma^{+}\left(x_{i}, t_{j}\right)}{k_{n}}$

where $k_{n}$ is the specific fracture stiffness.

Eq. (3) can be rewritten as

$\sigma^{+}\left(x_{i}, t_{j}\right)=\sigma^{-}\left(x_{i}, t_{j}\right)+\omega^{2} m_{n} \int_{0}^{t_{j}} v^{+}\left(x_{i}, t\right) d t$.

If the time interval, $\Delta t$, is small enough, the derivation of Eq. (4) with respect to $t$ becomes

$v^{+}\left(x_{i}, t_{j}\right)-v^{-}\left(x_{i}, t_{j}\right)=\frac{1}{k_{n}} \frac{\partial \sigma^{+}\left(x_{i}, t_{j}\right)}{\partial t}=\frac{1}{k_{n}} \frac{\sigma^{+}\left(x_{i}, t_{j+1}\right)-\sigma^{+}\left(x_{i}, t_{j}\right)}{\Delta t}$.

The stress-time response at the rear interface is

$\sigma^{+}\left(x_{i}, t_{j+1}\right)=\sigma^{+}\left(x_{i}, t_{j}\right)+k_{n} \Delta t\left[v^{-}\left(x_{i}, t_{j}\right)-v^{+}\left(x_{i}, t_{j}\right)\right]$.

Similarly, Eq. (6) can be expressed based on the stress-time response at the front interface

$v^{+}\left(x_{i}, t_{j}\right)-v^{-}\left(x_{i}, t_{j}\right)=\frac{1}{k_{n}} \frac{\sigma^{-}\left(x_{i}, t_{j+1}\right)-\sigma^{-}\left(x_{i}, t_{j}\right)}{\Delta t}$.

The stress-time response at the front interface is

$\sigma^{-}\left(x_{i}, t_{j+1}\right)=\sigma^{-}\left(x_{i}, t_{j}\right)+k_{n} \Delta t\left[v^{-}\left(x_{i}, t_{j}\right)-v^{+}\left(x_{i}, t_{j}\right)\right]$.

Substituting Eq. (7) into Eq. (1), the particle velocity-time response at the front interface is

$v^{-}\left(x_{i}, t_{j+1}\right)=\frac{1}{z}\left[z v^{+}\left(x_{i-1}, t_{j}\right)+\sigma^{+}\left(x_{i-1}, t_{j}\right)-\sigma^{-}\left(x_{i}, t_{j+1}\right)\right]$.

Substituting Eq. (9) into Eq. (2), the particle velocity-time response at the rear interface is

$v^{+}\left(x_{i}, t_{j+1}\right)=\frac{1}{z}\left[z v^{+}\left(x_{i+1}, t_{j}\right)-\sigma^{-}\left(x_{i+1}, t_{j}\right)+\sigma^{+}\left(x_{i}, t_{j+1}\right)\right]$.

The positive wave at the front interface of the filled fracture from each SHRB test is first converted into the particle velocity-time response, $v_{I}(t)$. When the boundary conditions $v^{+}\left(x_{1}, t\right)=v_{I}(t)$ and $\sigma^{+}\left(x_{1}, t\right)=\rho c v_{I}(t)$ and the initial conditions $v^{+}\left(x_{i}, t_{1}\right)=v^{-}\left(x_{i}, t_{1}\right)=$ 0 and $\sigma^{+}\left(x_{i}, t_{1}\right)=\sigma^{-}\left(x_{i}, t_{1}\right)=0(i \neq 1)$ are all known, the particle velocity-time responses $v^{-}\left(x_{i}, t\right)$ and $v^{+}\left(x_{i}, t\right)$ at the front and rear interfaces of the filled fracture can be calculated using Eqs. (10) and (11), respectively. The predicted wave transmission coefficient is

$T=\frac{\max \left[\varepsilon^{p+}\left(x_{i}, t\right)\right]}{\max \left[\varepsilon^{p-}\left(x_{i}, t\right)\right]}=\frac{\max \left[v^{+}\left(x_{i}, t\right)\right]}{\max \left[v^{-}\left(x_{i}, t\right)\right]}$

where $\varepsilon^{p-}\left(x_{i}, t\right)$ and $\varepsilon^{p+}\left(x_{i}, t\right)$ denote the positive waves at the front and rear interfaces, respectively. The particle velocity-time response is equal to the strain-time response multiplied by the P-wave velocity in the rock material, $v(x, t)=c \varepsilon(x, t)$.

\section{Experimental study}

The experimental study was conducted using an SHRB apparatus, described in detail by Wu et al. (2012). The schematic view of the 
SHRB apparatus and the $x-t$ diagram of P-wave propagation in this system can also be found in Wu et al. (2013c). The bar system has a square cross-section that is $40 \mathrm{~mm}$ on each side and includes a pair of $1500 \mathrm{~mm}$ long norite bars, namely, the incident bar and the transmitted bar, and a $200 \mathrm{~mm}$ long norite striker bar. A loading system, which uses a compressed spring with a stiffness coefficient of $9.52 \mathrm{~N} / \mathrm{mm}$ as the energy source, launches the striker bar at a low loading rate. A layer of filling materials is filled into a pre-set gap between the incident bar and the transmitted bar to simulate an artificial filled fracture. An aluminum box confines the filling materials to a uniaxial strain state during the test. A rubber disc, $10 \mathrm{~mm}$ in diameter and $1 \mathrm{~mm}$ in thickness, is used as a pulse shaper and is placed on the front end center of the incident bar to generate a non-dispersive longitudinal wave and to protect the contact ends of the striker bar and the incident bar.

The wave measurement, including signal triggering, data recording and data storage, is based on the LabVIEW platform. Two groups of strain gauges are mounted on each bar and are connected in a Wheatstone full-bridge to average out bending strain and to reduce signal noise. The strain gauge stations are $200 \mathrm{~mm}$ and $400 \mathrm{~mm}$ away from the fracture interfaces (the rear end of the incident bar and the front end of the transmitted bar). Because the half-wavelength of a generated sinusoidal pulse is $3000 \mathrm{~mm}$, the short lengths of the incident bar and the transmitted bar lead to the superposition of the positive and negative waves. A wave separation method (Zhao and Gary, 1997) is used to separate out the signal recorded from the strain gauge groups into the positive and negative waves. The strain-time responses at the fracture interfaces can be separately obtained by time shifting the positive and negative waves from those at the strain gauge stations on each bar. The stress-time response at the rear interface of the filled fracture, $\sigma^{+}\left(x_{i}, t\right)$, and the fracture closure-time response $\Delta u\left(x_{i}, t\right)$, can be obtained

$\sigma^{+}\left(x_{i}, t\right)=E\left(\varepsilon^{p+}\left(x_{i}, t\right)+\varepsilon^{n+}\left(x_{i}, t\right)\right)$

$$
\begin{aligned}
\Delta u\left(x_{i}, t\right) & =l_{s} \cdot \int_{0}^{t} \frac{v^{-}\left(x_{i}, t\right)-v^{+}\left(x_{i}, t\right)}{l_{s}} d t \\
& =c \int_{0}^{t}\left[\left(\varepsilon^{p-}\left(x_{i}, t\right)-\varepsilon^{n-}\left(x_{i}, t\right)\right)-\left(\varepsilon^{p+}\left(x_{i}, t\right)-\varepsilon^{n+}\left(x_{i}, t\right)\right)\right] d t
\end{aligned}
$$

where $E$ is the Young's modulus of the norite, $63.6 \mathrm{GPa}, c$ is the P-wave velocity in the norite, $6000 \mathrm{~m} / \mathrm{s}, l_{s}$ is the initial thickness of the filling materials, $\varepsilon^{n-}\left(x_{i}, t\right)$ and $\varepsilon^{n+}\left(x_{i}, t\right)$ denote the negative waves at the front and rear interfaces, respectively.

A validation test of the bar system needs to be performed by directly contacting the rear end of the incident bar to the front end of the transmitted bar (Fig. 2(a) inset). Fig. 2(a) shows that a half-cycle, sinusoidal pulse with a $2 \mathrm{kHz}$ frequency is successfully generated and the same wave amplitudes are recorded by four strain gauge groups during this test. This result indicates limited wave attenuation in the measuring range and dynamic stress equilibrium at the contact ends. Fig. 2(b) shows the stress-time responses of the fracture interfaces during the validation test. Dynamic stress equilibrium can be achieved (the stress-time responses are nearly coincident) during the first loading. Afterwards, the fracture interfaces lose contact, which is not taken into account. This figure also shows the integrity of the incident bar, the transmitted bar and the striker bar.

To prepare the filling materials, quartz sand with a single mineral composition was sieved to restrict the particle size between $1 \mathrm{~mm}$ and $2 \mathrm{~mm}$. The particle and bulk densities of the quartz sand are $2620 \mathrm{~kg} / \mathrm{m}^{3}$ and $1520 \mathrm{~kg} / \mathrm{m}^{3}$, respectively, and the porosity is $41 \%$. Kaolin clay was crushed and screened through a $0.25 \mathrm{~mm}$ sieve. The particle density, the bulk density and the porosity of the kaolin clay are $2630 \mathrm{~kg} / \mathrm{m}^{3}, 1631 \mathrm{~kg} / \mathrm{m}^{3}$ and $38 \%$, respectively. Kaolin clay was selected as the clay component because it is commonly found in natural
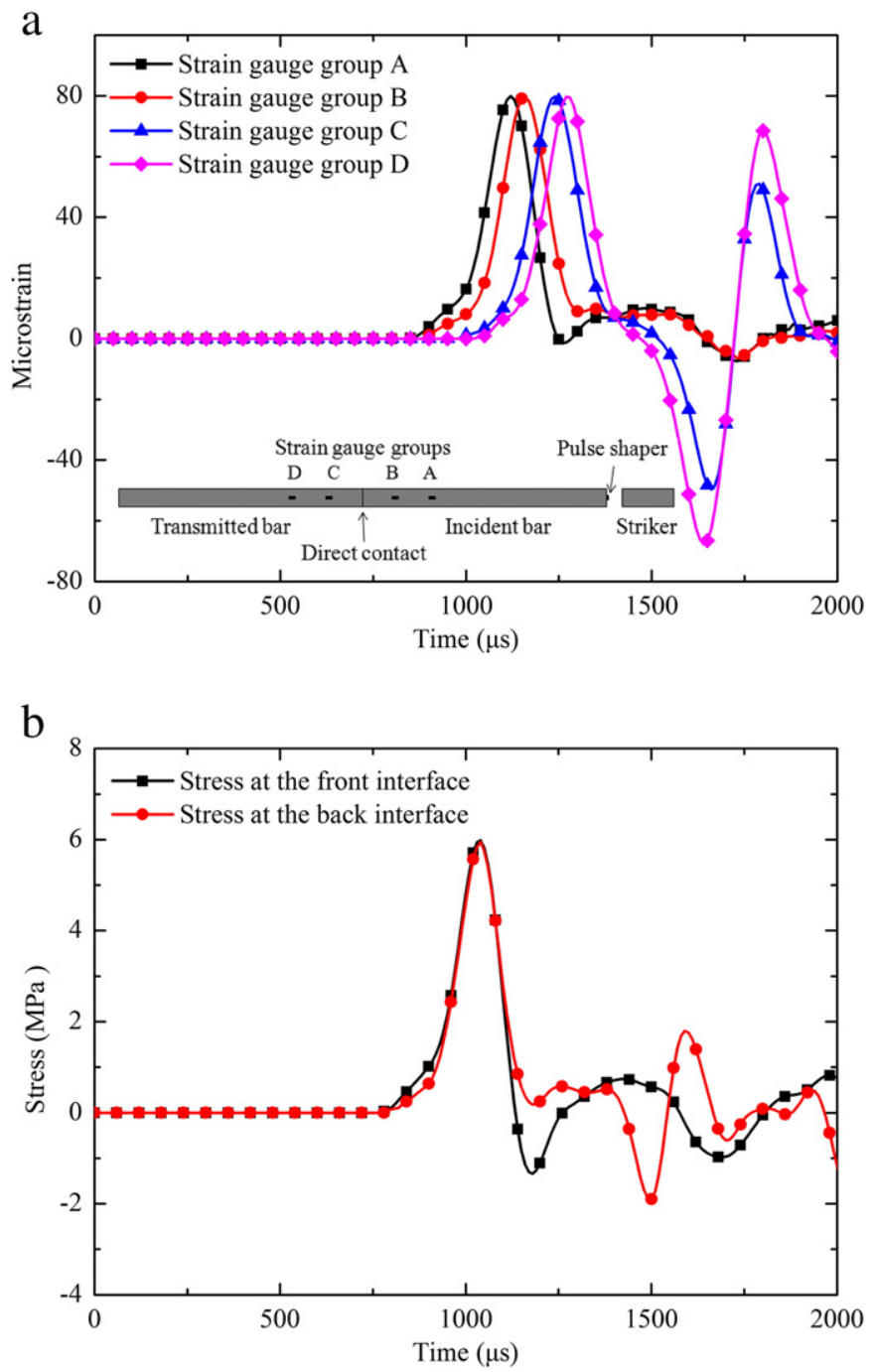

Fig. 2. A validation test result of the SHRB apparatus, (a) Recorded signal from strain gauge groups, the inset shows the validation test setup; (b) Dynamic stress equilibrium at the contact ends of the incident bar and the transmitted bar during the first loading.

rock discontinuities and is commercially available (Crawford et al., 2008). There were five groups of filling materials prepared. Each group weighed $250 \mathrm{~g}$, and the clay weight fractions were $0 \%, 30 \%, 50 \%$, $70 \%$ and $100 \%$. The dry quartz sand directly filled the gap between the incident bar and the transmitted bar. The other groups, with various clay weight fractions (30\%, 50\%, 70\% and $100 \%$ ), were first tumbled with $50 \mathrm{~g}$ pure water and were shaken manually, until the filling materials were visually homogeneous. The bulk densities of the filling materials with $30 \%, 50 \%$ and $70 \%$ clay weight fractions were $1555 \mathrm{~kg} / \mathrm{m}^{3}, 1575 \mathrm{~kg} / \mathrm{m}^{3}$ and $1598 \mathrm{~kg} / \mathrm{m}^{3}$, respectively. The filling materials then manually filled the gap without compaction and were maintained at a room condition for approximately $24 \mathrm{~h}$. Fig. 3 shows that the water contents of the filling materials with various clay weight fractions after the maintenance decrease to zero. Hence, the SHRB tests were conducted on the filled fracture under an air-dry condition.

\section{Results and discussion}

Fifteen experimental cases were investigated, including five clay weight fractions $(0,30 \%, 50 \%, 70 \%$ and $100 \%)$ and three filling material thicknesses ( $2 \mathrm{~mm}, 4 \mathrm{~mm}$ and $8 \mathrm{~mm}$ ). Three tests were performed for each case. A nearly constant loading rate of $40 \mathrm{GPa} / \mathrm{s}$ was used for 


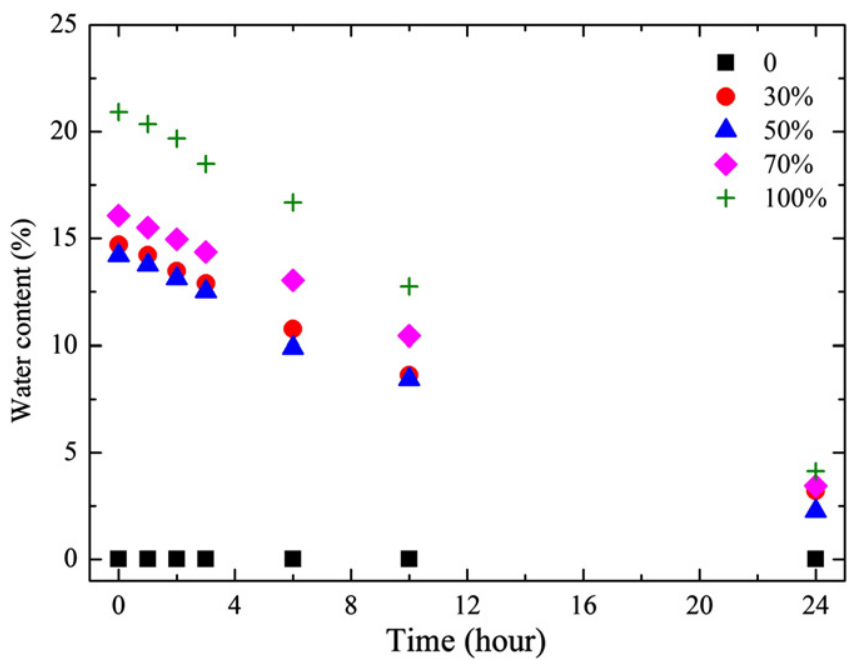

Fig. 3. Water content as a function of time in the preparation of filling materials with different clay weight fractions.

each test and was controlled using the same compressed spring length, $19.78 \mathrm{~mm}$. The loading rate was determined from the gradient of the pre-peak linear portion of the stress-time response at the front interface of a filled fracture.

\subsection{The stress-closure relation of a filled fracture}

Fig. 4(a) shows a typical test result recorded from P-wave propagation across a filled fracture. Test No. 4-2 is taken as an example. The experimental setup is shown in Fig. 4(a) inset. The amplitudes of the recorded waves from the incident and transmitted bars are dissimilar, owing to the differences in the positive and negative waves before and after the filled fracture. The original waves recorded by the strain gauge groups are analyzed to obtain the positive and negative waves that propagate in each bar and to obtain the stress-closure relation of the filled fracture.

The stress-time responses at the front and rear interfaces of the filled fracture are shown in Fig. 4(b). By comparing these responses to the validation test result (Fig. 2(b)), dynamic stress non-equilibrium (the stress-time responses are largely different at the rear interface of the filled fracture) is observed during P-wave propagation across the filled fracture. Wu et al. (2013c) revealed that the dynamic stress nonequilibrium across the filled fracture is mainly due to the existence of the filling materials, which delay the arrival time of the stress at the rear interface and consume a considerable amount of the incident energy during the dynamic compaction.

In the stress-closure relation of the filled fracture (Fig. 4(c)), the stress-time response at the rear interface is used to express the stress-time response of the filled fracture, which represents the portion of the incident energy that can travel through the filled fracture. The specific fracture stiffness is defined as the gradient of the tangent of the pre-peak linear portion of the stress-closure curve.

Fig. 5 shows the maximum stress and the corresponding closure from the stress-closure relation for each filled fracture as functions of the clay weight fraction and the filling material thickness. For the $2 \mathrm{~mm}$ thick filled fracture, the maximum stress of the fracture filled with the $30 \%$ clay weight fraction is larger than that of the fracture filled with the pure quartz sand. The maximum stress then continuously decreases with increasing clay weight fraction. The fracture closure at the maximum stress exhibits a reverse trend. The fracture filled with the $30 \%$ clay weight fraction has the smallest closure. For the $4 \mathrm{~mm}$ and $8 \mathrm{~mm}$ thick filled fractures, the results of the maximum stress and

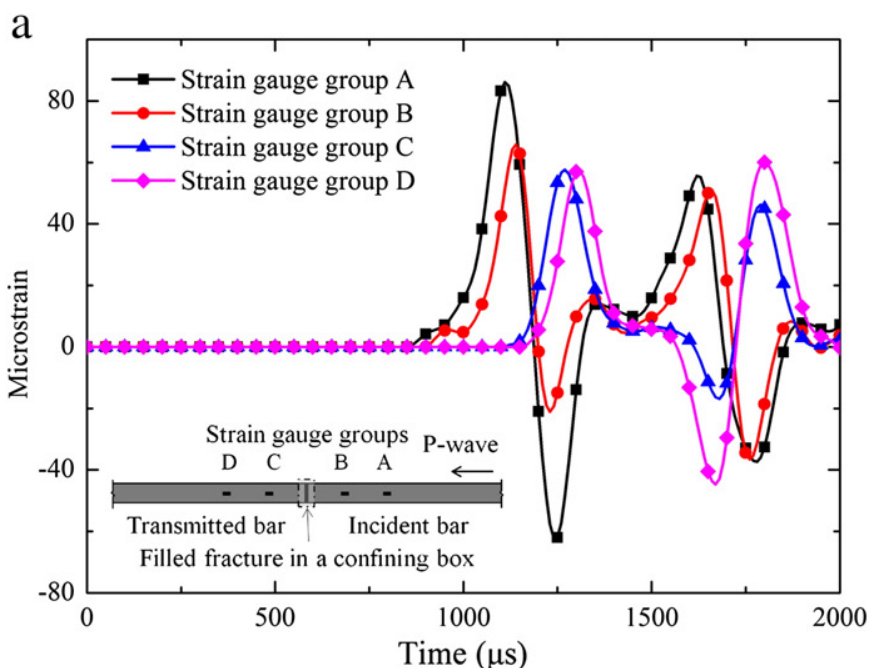

b

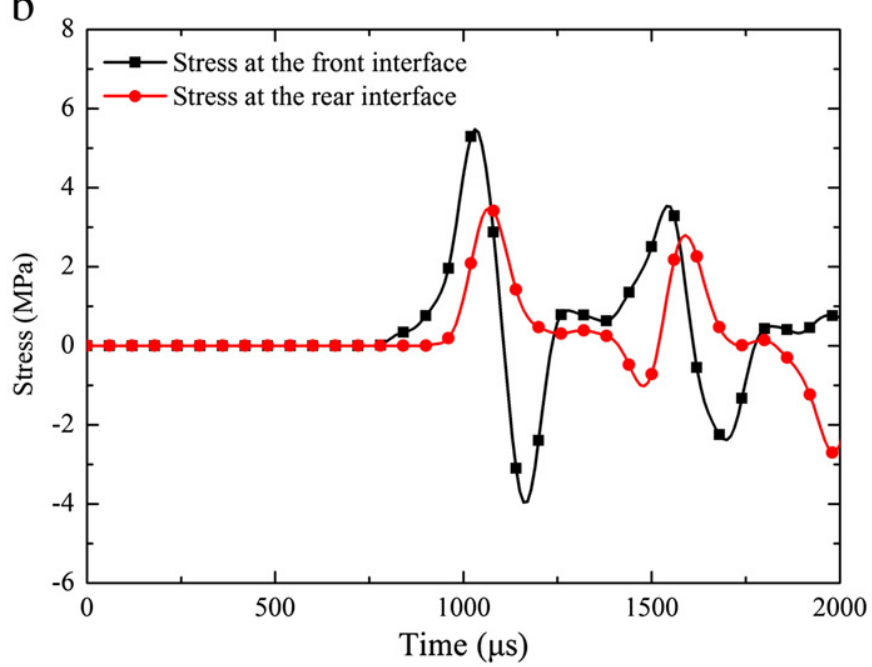

C

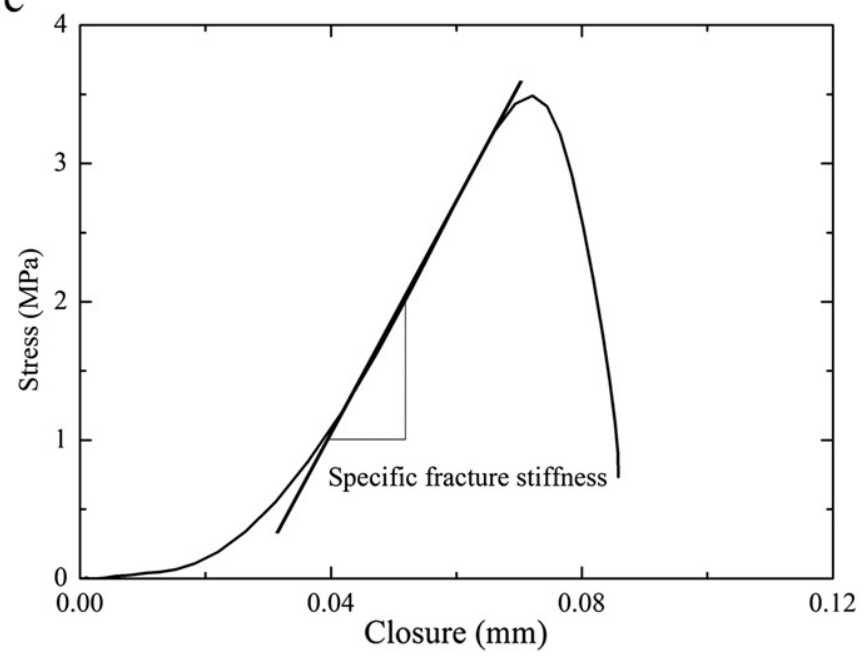

Fig. 4. A typical test result of P-wave propagation across a filled fracture, (a) Recorded signal from strain gauge groups, the inset shows the fracture setup; (b) Dynamic stress nonequilibrium across the filled fracture during the first loading; (c) Stress-closure relation of the filled fracture and the definition of specific fracture stiffness.

the corresponding closure are similar to those for the $2 \mathrm{~mm}$ thick fracture as a function of the clay weight fraction. The maximum stress decreases and the corresponding closure increases with increasing filling material thickness. 
a

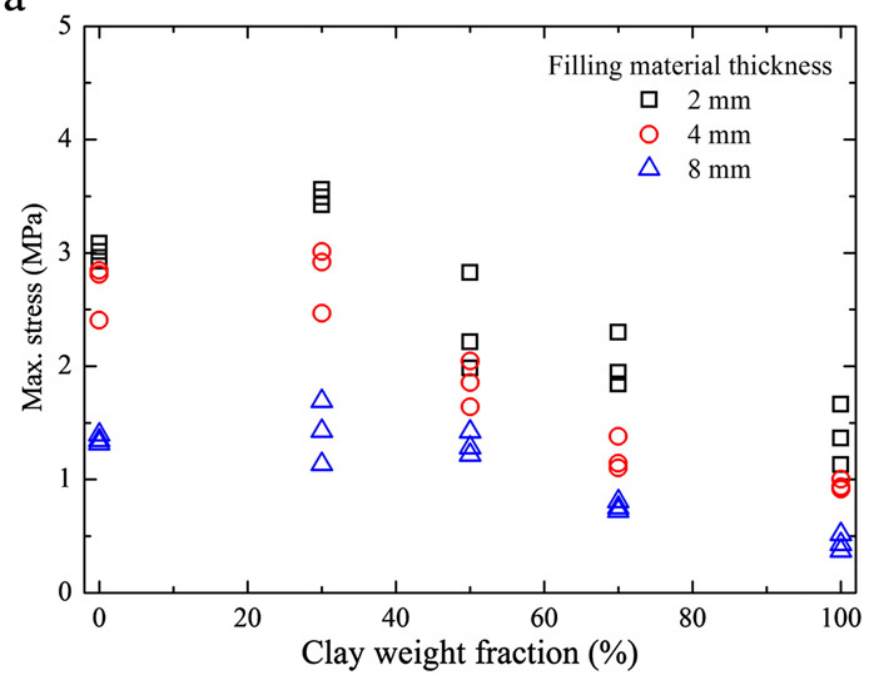

b

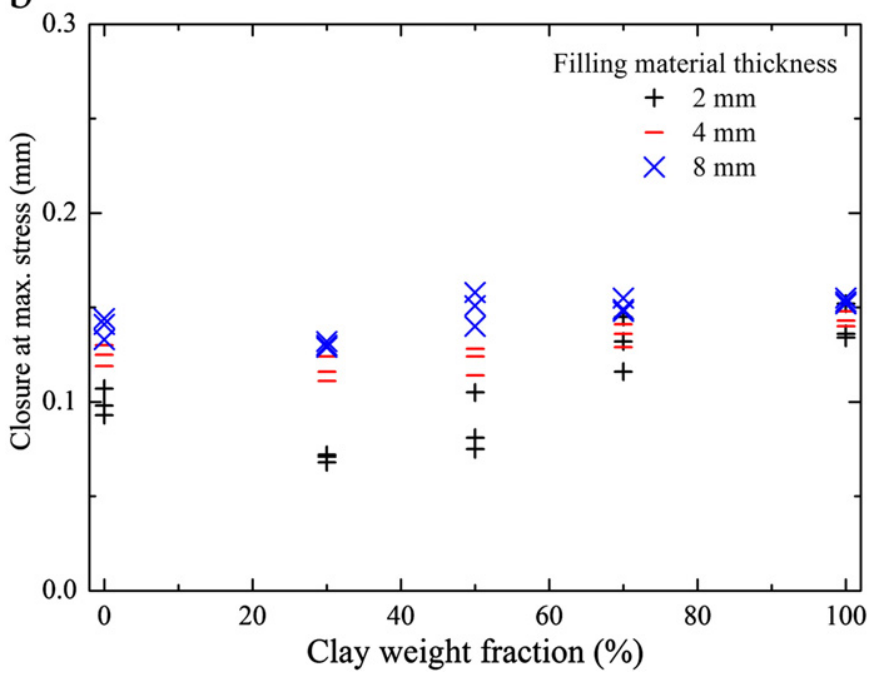

Fig. 5. Maximum stress (a) and the corresponding fracture closure (b) from stress-closure relation of each filled fracture as functions of clay weight fraction and filling material thickness.

\subsection{Wave transmission coefficient and seismic attenuation factor}

Fig. 6(a) shows the experimental results of the wave transmission coefficient as a function of the clay weight fraction. The wave transmission coefficient is directly measured from the SHRB test, which is the maximum stress of the transmitted wave over that of the incident wave. The measured wave transmission coefficient is also used to verify the predicted wave transmission coefficient (Table 1). For the same filling material thickness, the wave transmission coefficient for the fracture filled with the pure quartz sand is less than that for the fracture filled with $30 \%$ clay weight fraction. The wave transmission coefficient then decreases continuously with increasing clay weight fraction. The wave transmission coefficient for the filled fracture sharply decreases with increasing filling material thickness.

The energy attenuation across a filled fracture is due to the wave reflection and the dynamic compaction of filling materials and can be described by a seismic attenuation factor, $1 / Q$. Because this study focuses on the pre-peak linear portion of the stress-closure curve, the wave amplitude $\max \left[\varepsilon\left(x_{i}, t\right)\right]$ is proportional to the peak strain energy stored in a certain volume, $E_{P}$ (Aki and Richards, 2002). Hence, a relation
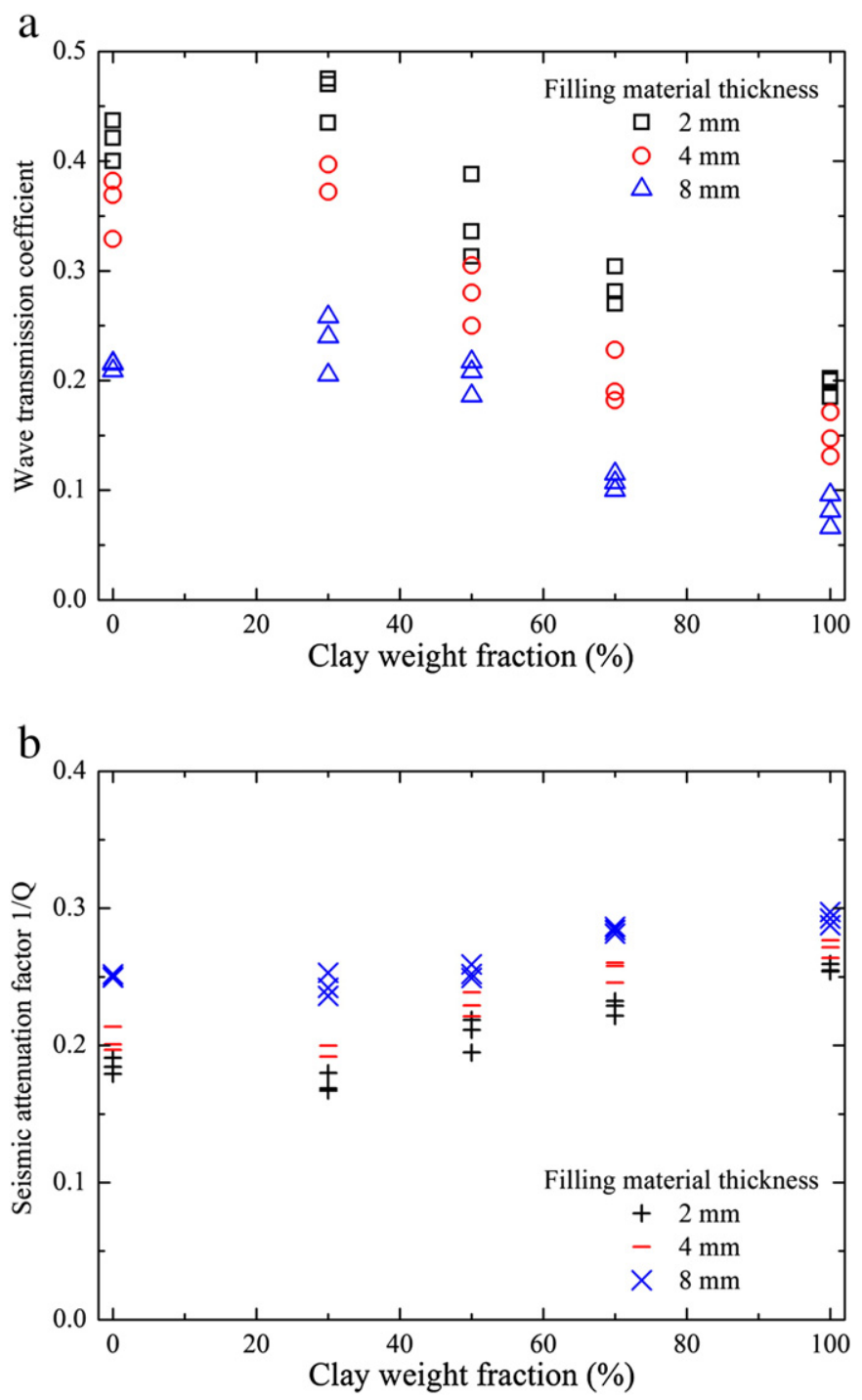

Fig. 6. Wave transmission coefficient (a) and seismic attenuation factor (b) as a function of clay weight fraction and filling material thickness.

between the seismic attenuation factor and the wave transmission coefficient, $T$, can be established

$$
\begin{aligned}
\frac{1}{Q} & =\frac{1}{\pi} \frac{E_{P R}+E_{P A}}{E_{P I}}=\frac{1}{\pi}\left(\frac{E_{P I}-E_{P T}}{E_{P I}}\right)=\frac{1}{\pi}\left(1-\frac{\max \left[\varepsilon^{p+}\left(x_{i}, t\right)\right]}{\max \left[\varepsilon^{p-}\left(x_{i}, t\right)\right]}\right) \\
& =\frac{1}{\pi}(1-T)
\end{aligned}
$$

where the peak incident energy, $E_{P I}$, is the sum of the peak reflected energy, $E_{P R}$, the peak transmitted energy, $E_{P T}$, and the peak attenuated energy in the filled fracture, $E_{P A}$.

Fig. 6(b) shows that the seismic attenuation factor as a function of the clay weight fraction. The measured wave transmission coefficient is used to calculate this factor. The seismic attenuation factor increases with increasing filling material thickness. The seismic attenuation factor of the fracture filled with the $30 \%$ clay weight fraction is smaller than that of the fracture filled with the pure quartz sand. The seismic attenuation factor then continuously increases with increasing clay weight fractions. When the clay weight fraction increases from pure quartz sand $(0 \%)$ to a pure clay matrix (100\%), this factor exhibits a reverse trend compared with the wave transmission coefficient. 
Table 1

Experimental and analytical results of the interaction between a P-wave and a filled fracture.

\begin{tabular}{|c|c|c|c|c|c|}
\hline \multirow[t]{2}{*}{ Test no. } & \multirow[t]{2}{*}{ Clay content (\%) } & \multirow{2}{*}{$\begin{array}{l}\text { Filling material } \\
\text { thickness (mm) }\end{array}$} & \multicolumn{2}{|l|}{ Experimental results } & \multirow{2}{*}{$\frac{\text { Analytical results }}{\text { Wave transmission coefficient }}$} \\
\hline & & & Specific fracture stiffness $(\mathrm{MPa} / \mathrm{mm})$ & Wave transmission coefficient & \\
\hline $1-1$ & 0 & 2 & 33.518 & 0.400 & 0.430 \\
\hline $1-2$ & 0 & 2 & 35.870 & 0.421 & 0.449 \\
\hline $1-3$ & 0 & 2 & 39.759 & 0.437 & 0.466 \\
\hline $2-1$ & 0 & 4 & 28.155 & 0.382 & 0.385 \\
\hline $2-2$ & 0 & 4 & 22.327 & 0.329 & 0.359 \\
\hline $2-3$ & 0 & 4 & 26.498 & 0.369 & 0.373 \\
\hline $3-1$ & 0 & 8 & 11.144 & 0.216 & 0.217 \\
\hline $3-2$ & 0 & 8 & 12.110 & 0.209 & 0.220 \\
\hline $3-3$ & 0 & 8 & 13.011 & 0.215 & 0.241 \\
\hline $4-1$ & 30 & 2 & 44.075 & 0.470 & 0.509 \\
\hline $4-2$ & 30 & 2 & 45.744 & 0.435 & 0.485 \\
\hline $4-3$ & 30 & 2 & 44.827 & 0.475 & 0.512 \\
\hline 5-1 & 30 & 4 & 26.141 & 0.372 & 0.392 \\
\hline $5-2$ & 30 & 4 & 29.148 & 0.397 & 0.401 \\
\hline $5-3$ & 30 & 4 & 31.263 & 0.397 & 0.407 \\
\hline $6-1$ & 30 & 8 & 11.241 & 0.205 & 0.234 \\
\hline $6-2$ & 30 & 8 & 13.768 & 0.240 & 0.265 \\
\hline $6-3$ & 30 & 8 & 16.059 & 0.258 & 0.269 \\
\hline 7-1 & 50 & 2 & 33.302 & 0.388 & 0.397 \\
\hline $7-2$ & 50 & 2 & 28.708 & 0.313 & 0.384 \\
\hline $7-3$ & 50 & 2 & 28.707 & 0.336 & 0.415 \\
\hline 8-1 & 50 & 4 & 15.224 & 0.250 & 0.253 \\
\hline $8-2$ & 50 & 4 & 16.593 & 0.280 & 0.269 \\
\hline $8-3$ & 50 & 4 & 17.970 & 0.305 & 0.285 \\
\hline $9-1$ & 50 & 8 & 8.466 & 0.186 & 0.162 \\
\hline $9-2$ & 50 & 8 & 10.512 & 0.217 & 0.202 \\
\hline $9-3$ & 50 & 8 & 10.004 & 0.208 & 0.189 \\
\hline $10-1$ & 70 & 2 & 19.620 & 0.270 & 0.298 \\
\hline $10-2$ & 70 & 2 & 19.864 & 0.281 & 0.304 \\
\hline $10-3$ & 70 & 2 & 20.452 & 0.304 & 0.323 \\
\hline $11-1$ & 70 & 4 & 12.836 & 0.228 & 0.222 \\
\hline $11-2$ & 70 & 4 & 10.795 & 0.190 & 0.213 \\
\hline $11-3$ & 70 & 4 & 11.052 & 0.182 & 0.199 \\
\hline $12-1$ & 70 & 8 & 5.138 & 0.100 & 0.102 \\
\hline $12-2$ & 70 & 8 & 5.986 & 0.107 & 0.123 \\
\hline $12-3$ & 70 & 8 & 5.519 & 0.115 & 0.115 \\
\hline $13-1$ & 100 & 2 & 12.714 & 0.202 & 0.207 \\
\hline $13-2$ & 100 & 2 & 11.331 & 0.185 & 0.191 \\
\hline $13-3$ & 100 & 2 & 12.740 & 0.200 & 0.217 \\
\hline $14-1$ & 100 & 4 & 8.455 & 0.147 & 0.153 \\
\hline $14-2$ & 100 & 4 & 8.378 & 0.131 & 0.158 \\
\hline $14-3$ & 100 & 4 & 9.191 & 0.171 & 0.171 \\
\hline $15-1$ & 100 & 8 & 3.117 & 0.066 & 0.069 \\
\hline $15-2$ & 100 & 8 & 3.653 & 0.096 & 0.083 \\
\hline $15-3$ & 100 & 8 & 3.304 & 0.081 & 0.073 \\
\hline
\end{tabular}

\subsection{The packing model}

According to a simple packing model proposed by Clarke (1979), the porosity of the sand-clay mixture can be described by the following cases: (a) When the clay volume fraction $V_{c}$ is less than the void space among the sand particles $\varphi_{s}$, the porosity of the mixture $\varphi$ decreases with increasing clay volume fraction $V_{c}$ (Eq. (16)). (b) When the clay volume fraction $V_{c}$ is equal to the void space $\varphi_{s}$, the porosity $\varphi$ reaches a minimum value $\varphi_{\min }$ and is determined by the porosity of the clay matrix $\varphi_{c}$ that fills the void space $\varphi_{s}$ (Eq. (17)). (c) When the clay volume fraction $V_{c}$ is greater than the void space $\varphi_{s}$, the porosity $\varphi$ depends on the clay volume fraction $V_{c}$ and on the clay porosity $\varphi_{c}$ (Eq. (18)).

$\varphi=\varphi_{s}-V_{c}\left(1-\varphi_{c}\right) \quad$ for $V_{c}<\varphi_{s}$

$\varphi=\varphi_{\min }=\varphi_{s} \cdot \varphi_{c} \quad$ for $V_{c}=\varphi_{s}$

$\varphi=V_{c} \cdot \varphi_{c}$ for $V_{c}>\varphi_{s}$.

The packing model of the sand-clay mixture shows that the porosity of the mixture depends on the relation between the clay volume

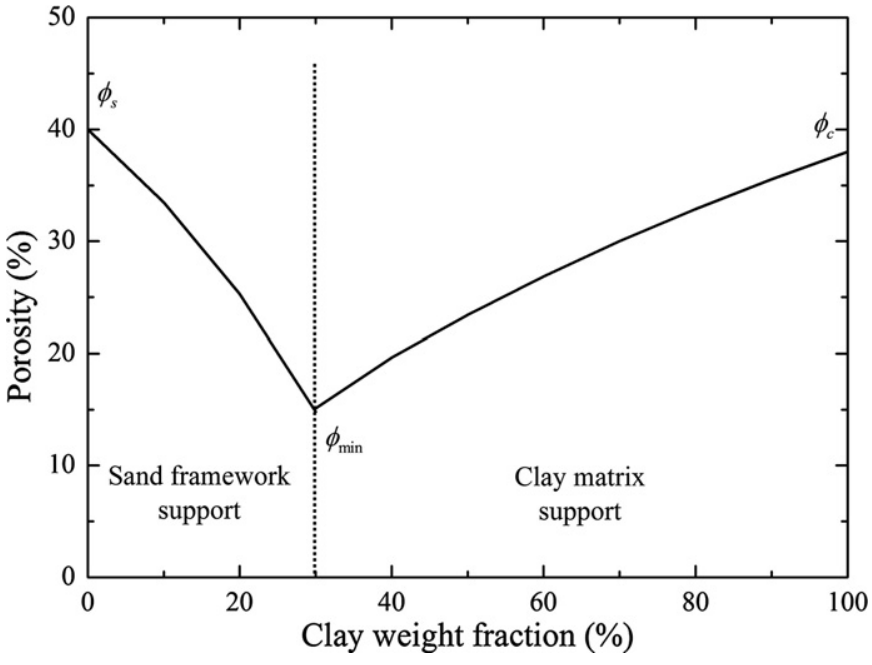

Fig. 7. The porosity of the sand-clay mixture as a function of clay weight fraction. 
fraction and the void space among the sand particles. To build a packing model that is a function of the clay weight fraction $\omega_{c}$, the clay volume fraction is converted into the clay weight fraction using the transforms proposed by Marion et al. (1992),

$\omega_{c}=\frac{V_{c}\left(1-\varphi_{c}\right) \rho_{c}}{V_{c}\left(1-\varphi_{c}\right) \rho_{c}+\left(1-\varphi_{s}\right) \rho_{s}}$ for $V_{c}<\varphi_{s}$

$\omega_{c}=\frac{V_{c}\left(1-\varphi_{c}\right) \rho_{c}}{V_{c}\left(1-\varphi_{c}\right) \rho_{c}+\left(1-V_{c}\right) \rho_{s}}$ for $V_{c}>\varphi_{s}$

where $\rho_{s}$ is the density of quartz sand, and $\rho_{c}$ is the density of kaolin clay.

Fig. 7 plots the porosity of the sand-clay mixture as a function of the clay weight fraction. This figure shows that the porosity reaches a minimum value of $15 \%$ at an approximately $30 \%$ clay weight fraction. The sand particles sustain the mixture when the clay weight fraction is less than $30 \%$, while the clay matrix supports the mixture when the clay weight fraction is greater than $30 \%$. This result also shows that in the mixture with the $30 \%$ clay weight fraction the kaolin clay can completely fill the void space among the sand particles.

\subsection{Packing mechanism of the sand-clay mixture}

For the sand framework support, sand compaction develops from a low stiffness at a small strain due to inter-particle contacts to a high stiffness at a large strain due to packing densification (Cho et al., 2006). Fig. 8(a) inset shows that the particle surface is rough to some degree and determines particle contacts. The sieve analysis on sand particles before and after the test shows that most of sand particles keep elastic deformation and a few sand particles (about 2.5\% weight fraction) are crushed into fine particles. The sand particles support the dynamic stress in the form of stress chains (Majmudar and Behringer, 2005). Hence, the stress in this study is too low to cause the contact damage of sand particles.

For the clay matrix support, the kaolin clay contains a weak-bonded and layered particle structure (Mitchell and Soga, 2005) and a void

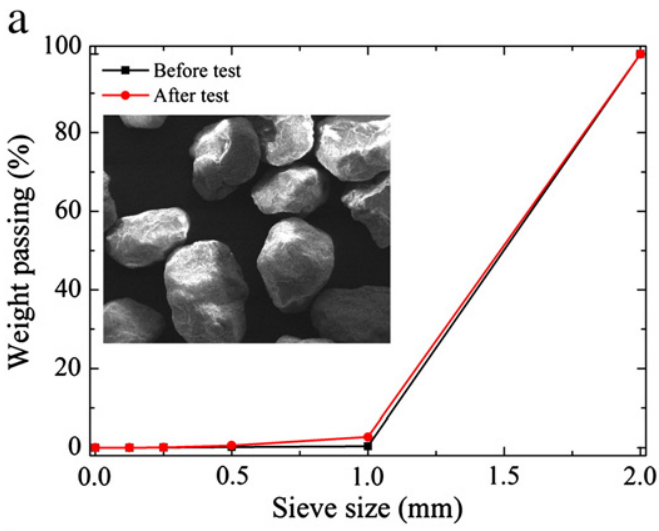

b

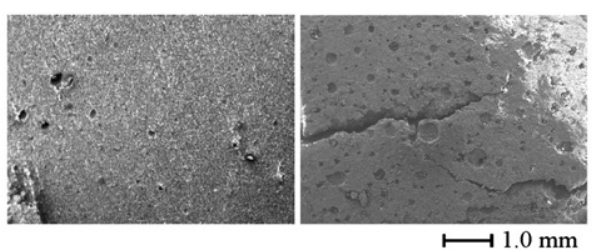

Fig. 8. (a) A sieve analysis on sand particles in the fracture filled with the pure quartz sand before and after the test, the inset shows the microstructure observation on original sand particles; (b) Microstructure observations on the clay matrix in the fracture filled with the pure kaolin clay before the test (left) and after the test (right) based on a Scanning Electron Microscope at $20 \times$ magnification. space among non-abrasive and soft particles (Murray, 2007). The experimental results show that the maximum stress of the pure quartz sand is much larger than that of the pure clay matrix (see Fig. 5(a)), indicating that the particle contact in the quartz sand is stronger than that in the kaolin clay. The microstructure observations on the pure clay matrix before and after the test show that the contact damage appears after the dynamic stress (Fig. 8(b)). Fortin et al. (2007) revealed that the clay damage is accompanied by pore collapse and by grain crushing and consumes the incident energy. Hence, a heavy damage is induced in the clay matrix at the low stress level and consumes a considerable amount of the incident energy.

From above discussion, we can find that the sand particles support the mixture with the $30 \%$ clay weight fraction and the clay matrix in the void space may also assist wave transmission, and thus this mixture exhibits the smallest seismic attenuation factor. When the clay weight fraction is greater than $30 \%$ and the clay matrix supports the mixture, the irregular damage in the clay matrix may induce the fracture response to become scatter (such as the closure at the maximum stress in Fig. 5(b)).

\subsection{The interaction between a P-wave and a filled fracture}

The interaction between a P-wave and a filled fracture is represented by the specific fracture stiffness and by the wave transmission coefficient. The analytical and experimental results of the interaction between a P-wave and a filled fracture are shown in Table 1. In the method of characteristic lines, the DSDM is used, in which the incident wave is expressed as the particle velocity-time response and the specific fracture stiffness measured from each test is used to calculate the wave transmission coefficient. The predicted wave transmission coefficient agrees well with the measured wave transmission coefficient for each test. The DSDM describes the boundary conditions of the filled fracture and establishes a relation between the specific fracture stiffness and the wave transmission coefficient in the time domain.

According to Figs. 5(a) and 9, the specific fracture stiffness of the filled fracture exhibits a trend similar to that of the maximum stress as a function of the clay weight fraction. For the same filling material thickness, the specific fracture stiffness of the fracture filled with the pure quartz sand is less than that of the fracture filled with the 30\% clay weight fraction. The specific fracture stiffness then decreases continuously with increasing clay weight fraction. The fracture filled with the $30 \%$ clay weight fraction has the largest specific fracture stiffness because it has the largest maximum stress, the smallest corresponding closure and the smallest seismic attenuation factor. The specific fracture stiffness of the filled fracture sharply decreases with increasing filling material thickness. The wave transmission coefficient exhibits a trend similar to that of the specific fracture stiffness as functions of the filling material thickness and the clay weight fraction. The larger maximum stress indicates that a higher transmitted wave amplitude, and a smaller corresponding closure mean less filling material compaction. Therefore, the filled fracture with a larger maximum stress and a smaller corresponding closure has a larger wave transmission coefficient.

Fig. 9 indicates that the wave transmission coefficient increases with increasing specific fracture stiffness. This increase in the wave transmission coefficient is attributed to increasing normal stress, resulting in larger specific fracture stiffness. It is also observed that the wave transmission coefficient and the specific fracture stiffness have a linear relation, regardless of the filling material composition or the filling material thickness. This observation is similar to that from a previous study on P-wave propagation across a non-filled fracture (Zhao et al., 2008).

\section{Conclusions}

This study investigates the role of filling materials in the interaction between a P-wave and a filled fracture. The stress and displacement 


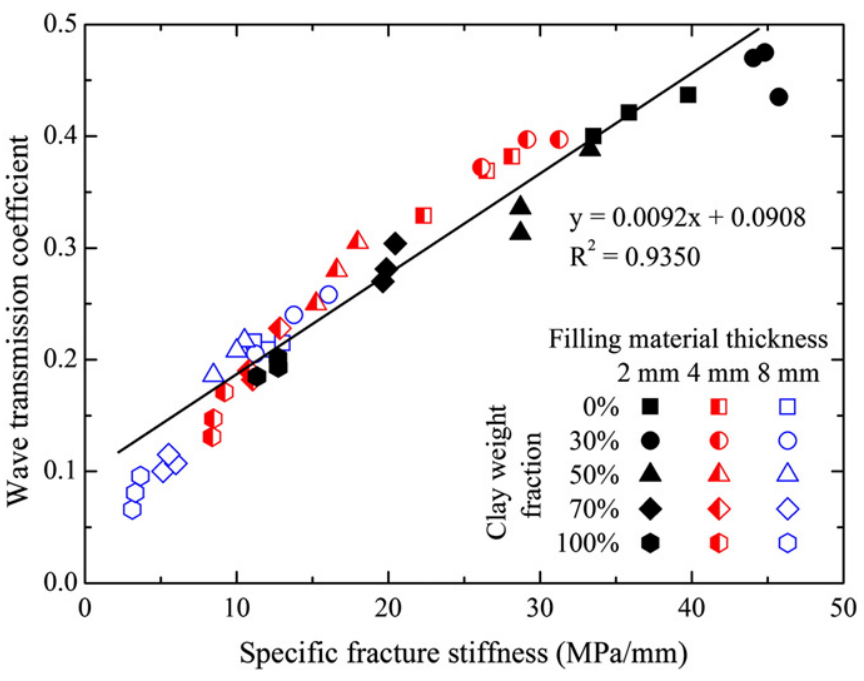

Fig. 9. Wave transmission coefficient as a function of specific fracture stiffness.

discontinuity model describes the boundary conditions of the filled fracture. This model is used to predict the wave transmission coefficient based on the method of characteristic lines, and the predicted results agree well with the experimental results. The filling material composition strongly affects the dynamic compaction, which is also related to the filling material thickness. For the same filling material thickness, the specific fracture stiffness of the fracture filled with the $30 \%$ clay weight fraction is larger than that of the fracture filled with the pure quartz sand. The specific fracture stiffness then decreases with increasing clay weight fraction. This result is due to the fact that the filled fracture exhibits the largest maximum stress, the smallest corresponding closure and the smallest seismic attenuation factor when the clay matrix completely fills the void space of the quartz sand. The wave transmission coefficient exhibits a trend similar to that of the specific fracture stiffness. There is a linear relation observed between the wave transmission coefficient and the specific fracture stiffness, regardless of the filling material composition or the filling material thickness.

\section{Acknowledgment}

This work is sponsored by the Swiss National Science Foundation (200021_124846).

\section{References}

Aki, K., Richards, P.G., 2002. Quantitative Seismology. University Science Books, California. Bedford, A., Drumheller, D.S., 1994. Introduction to Elastic Wave Propagation. JohnWiley \& Sons, Chichester.

Cho, G.C., Dodds, J., Santamarina, J.C., 2006. Particle shape effects on packing density, stiffness, and strength: natural and crushed sands. J. Geotech. Geoenviron. Eng. ASCE 132, 591-602.

Clarke, R.H., 1979. Reservoir properties of conglomerates and conglomeratic sandstones. Am. Assoc. Pet. Geol. Bull. 63, 799-809.

Crawford, B.R., Faulkner, D.R., Rutter, E.H., 2008. Strength, porosity, and permeability development during hydrostatic and shear loading of synthetic quartz-clay fault gouge. J. Geophys. Res. 113, B03207.

Fortin, J., Gueguen, Y., Schubnel, A., 2007. Effects of pore collapse and grain crushing on ultrasonic velocities and Vp/Vs. J. Geophys. Res. 112, B08207.

Ma, G.W., Li, J.C., Zhao, J., 2011. Three-phase medium model for filled rock joint and interaction with stress waves. Int. J. Numer. Anal. Methods Geomech. 35, 97-110.

Majmudar, T.S., Behringer, R.P., 2005. Contact force measurements and stress-induced anisotropy in granular materials. Nature 435, 1079-1082.

Marion, D., Nur, A., Yin, H., Han, D., 1992. Compressional velocity and porosity in sand-clay mixtures. Geophysics 57, 554-563.

Mitchell, J.K., Soga, K., 2005. Fundamentals of Soil Behavior. JohnWiley \& Sons, New Jersey. Murray, H.H., 2007. Applied Clay Mineralogy. Elsevier, Amsterdam.

Wu, W., Li, J.C., Zhao, J., 2012. Loading rate dependency of dynamic responses of rock fractures at low loading rate. Rock Mech. Rock. Eng. 45, 421-426.

Wu, W., Zhu, J.B., Zhao, J., 2013a. A further study on seismic response of a set of parallel rock fractures filled with viscoelastic materials. Geophys. J. Int. 192, 671-675.

Wu, W., Li, J.C., Zhao, J., 2013b. Seismic response of adjacent filled parallel rock fractures with dissimilar properties. J. Appl. Geophys. 96, 33-37.

Wu, W., Zhu, J.B., Zhao, J., 2013c. Dynamic response of a rock fracture filled with viscoelastic materials. Eng. Geol. 160, 1-7.

Zhao, H., Gary, G., 1997. A new method for the separation of waves: application to the SHPB technique for an unlimited duration of measurement. J. Mech. Phys. Solids 45, 1185-1202.

Zhao, X.B., Zhao, J., Cai, J.G., 2006. P-wave transmission across fractures with nonlinear deformational behavior. Int. J. Numer. Anal. Methods Geomech. 30, 1097-1112.

Zhao, J., Cai, J.G., Zhao, X.B., Li, H.B., 2008. Dynamic model of fracture normal behavior and application to prediction of stress wave attenuation across fractures. Rock Mech. Rock. Eng. 41, 671-693.

Zhu, J.B., Perino, A., Zhao, G.F., Barla, G., Li, J.C., Ma, G.W., Zhao, J., 2011. Seismic response of a single and a set of filled joints of viscoelastic deformational behavior. Geophys. J. Int. 186, 1315-1330. 